\title{
The effect of hemodialysis on the body composition and cardiovascular disease markers in recently diagnosed end stage renal disease patients
}

\author{
Umut Cakiroglu ${ }^{1}$ \\ Hakan Akdam ${ }^{1}$ \\ Ufuk Eryilmaz ${ }^{2}$ \\ Cagdas Akgullu² \\ Ozgul Ozbek ${ }^{1}$ \\ Aslihan Karul Büyüköztürk³ \\ (iD) Harun Akar ${ }^{4}$ \\ Yavuz Yeniceriog/u'
}

1. Adnan Menderes University, Medical School, Department of Nephrology, Aydın/Turkey 2. Adnan Menderes University, Medical School, Department of Cardiology, Aydın/Turkey 3. Adnan Menderes University, Medical School, Department of Biochemistry, Aydın/Turkey 4. University of Health Sciences, Izmir Tepecik Health Research and Application Center, Department of Internal Medicine, Izmir/Turkey

\section{SUMMARY}

AIM: Uremic toxins and excess fluid contributes to increased cardiovascular (CV) risk. We aimed to determine the body fluid status in patients who are just starting hemodialysis (HD) and to determine the effects of excess fluid removed by HD on the CV system.

METHODS: A total of 52 patients with chronic kidney disease (CKD) who had just started HD were included. Before the HD, the left atrial diameter was measured, the volumes were calculated, the pulse wave velocity $(P W V)$ and the augmentation index $(A \mid x)$ were measured, the bioimpedance analysis (BIA) was performed, the blood was taken for brain natriuretic peptide (BNP). When patients reached their dry weight with $H D$, the same measurements were repeated.

RESULTS: Measurements were made to determine the volume status, and all parameters except the fat tissue index decreased significantly after HD. With the removal of fluid by HD, there was an average weight reduction of 4.38 kilograms. Positive correlations between PWV and age and cardiothoracic ratio (CTR) before HD were determined. Negative correlations were found between PWV and lean tissue mass (LTM) and intracellular water (ICW) before HD. At the end of the last HD, PWV was positively correlated with age, CTR, central pulse pressure Correlation between pulse wave velocity and LTI was negative

CONCLUSIONS: HD significantly improves PWV in patients reaching dry weight. Reduction of fluid excess by ultrafiltration in HD patients may reduce $C V$ mortality by reducing arterial stiffness.

KEYWORDS: Pulse wave analysis. Natriuretic peptide, brain. Kidney diseases. Kidney failure, chronic. Electric impedance. Renal dialysis. Body composition.

\section{INTRODUCTION}

The incidence and prevalence of chronic kidney disease (CKD) has increased day by day and has become an important public health problem. ${ }^{1}$ The most important cause of mortality and morbidity in patients with CKD is cardiovascular disease (CVD). Inadequate ultrafiltration (UF) will cause patients to be exposed to fluid and pressure loads, while excessive UF will cause undesirable side effects, particularly hy- potension, during dialysis. ${ }^{2}$ In this study, we aimed to investigate the effect of reducing the fluid excess and correcting the uremic state on the cardiovascular system in patients with end-stage renal disease (ESRD) (with new onset dialysis). For this reason, echocardiography, arterial stiffness, pro-BNP and bioimpedance were used to assess CVD and volume status of patients before dialysis. The same parameters were repeated after the patients reached dry weight.

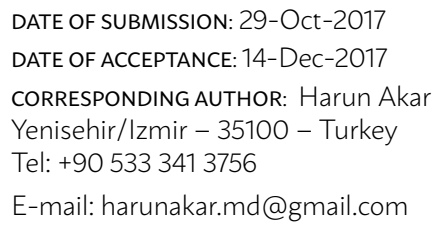

drumutcakiroglu@hotmail.com, akdamhakan@yahoo.com drufukeryilmaz@gmail.com, cagdasakgullu@gmail.com ozgulozbek48@gmail.com, abkarul@yahoo.com harunakar.md@gmail.com, yyenicerioglu@gmail.com 


\section{MATERIALS AND METHODS}

A total of 52 patients (18-75 years old) who were admitted to the nephrology outpatient clinic and the emergency department for ESRD and who had just started HD were included in the study. Participants who were informed about the study were voluntarily included in the work after their signed approval. In our study, the exclusion criteria are listed below: Patients with cardiac arrhythmia, patients with coronary artery disease, patients with peripheral arterial disease, patients who have had stents in coronary arteries or underwent bypass surgery, patients with metal lid, stent, metal suture or metal prosthesis, patients with malignancy, patients with active infection during the study, pregnancy, patients who are not hemodynamically stable during the use of the device.

Detailed medical histories were obtained from all the subjects studied, general physical examination was performed, heart rate and arterial blood pressure recorded. Measurements of height and weight, body composition and volume, arterial stiffness, and echocardiographic measurements were performed. The body mass indexes were calculated by dividing the weight of the patients in kilograms by the height of the body in meters. [Body mass index $\left(\mathrm{kg} / \mathrm{m}^{2}\right)=$ weight / (height) ${ }^{2}$. Body surface area (BSA) was calculated using the DuBois formula by the patients' height $(\mathrm{cm})$ and weight $(\mathrm{kg})$ [BSA $(\mathrm{m} 2)=$ (height 0.425 $\mathrm{x}$ weight 0.725) x 0.007184]. Age, gender, primary renal disease, hypertension, presence or absence of $\mathrm{DM}$, medication usage, smoking status were recorded for all the subjects who were taken into the study.

\section{LABORATORY ANALYSIS}

BNP levels were measured before and after HD. BNP levels above $100 \mathrm{pg} / \mathrm{mL}$ were assessed in relation to heart failure. Hemoglobin, hematocrit, leukocyte, thrombocyte, total protein, albumin, globulin, sodium, potassium, calcium, phosphate, total cholesterol, HDL cholesterol, LDL cholesterol, triglyceride, PTH, CRP, ferritin and serum iron levels were measured using Architect System Kits (With the Abbott II2000SR model Architect plus (serial number ISR0746).

\section{Arterial Stiffness Measurement}

A single-armed arteriograph device (Mobil-OGraph PWA model pulse wave analyzer, branded by I.E.M. GmbH), which has proven to be reliable for the measurement (user-independent, measuring with oscillometric method) was used. Patients included in the study were allowed to rest for 10 minutes before measurement. They were asked not to smoke or drink caffeinated beverages within the 30 minutes prior to the measurement. For each individual, date of birth, height, weight, smoking information was entered into the program of the device. While the patients were sitting, a suitable cuff was placed in the upper arm on the non-arteriovenous fistula. Three consecutive measurements were taken automatically with 30 seconds of duration. Measurements were made just before the first hemodialysis treatment on admission and after the last hemodialysis treatment before the discharge. As a measurement principle, the device was inflated so that the cuff could be at least $35 \mathrm{~mm} \mathrm{Hg}$ above the currently detected systolic pressure. Thus, occlusion of the brachial artery was performed and blood flow was stopped for approximately 8-20 seconds during the measurement period. It is important to point ou that in the stop-flow condition, a membrane is formed in the brachial artery at the upper border of the inflated cuff. As air in the cuff is evacuated, arterial movement causes pressure changes in the cuff. ${ }^{3}$ Pressure fluctuations become noticeable in the diaphragm when the central pressure changes and early (direct, P1) and late (reflected P2) systolic and diastolic waves reach the occlusion region. These small, weak pressure changes can be detected by the high-resolution pressure sensors of the arteriography, which are then amplified and scanned with a special tonometer. These changes were then evaluated by a computer. Systolic pressure, rapid increase of oscillations, average pressure, the most acute point of oscillations and diastolic pressure, all showed the point where oscillations disappeared rapidly. ${ }^{4}$ This way, peripheral blood pressures, central systolic blood pressure, central diastolic blood pressure, central pulse pressure, cardiac output (CO), augmentation index and pulse wave velocity could be measured. Similar to the measurements made with the central pressure catheter, subclavian, axillary and brachial arteries act as cannula to transmit the central pressure changes to the sensor. The signals obtained through the oscillometer were transmitted to the computer via infrared, wireless communication network. ${ }^{5}$

Body Composition and Volume Measurement Bioimpedance is based on the principle that an 
alternating current is applied to the human body and a vector size called impedance $(\mathrm{Z})$ is measured. Volume status and body composition were measured using a portable multifrequency bioimpedance spectroscopy device (BCM ${ }^{\circledR}$ Fresenius Medical Care D, $\mathrm{GmbH})^{6}$ Those involved in the study were placed in a flat lying position on the back. When bioimpedance measurements were made, the arm without arteriovenous dialysis fistula was used. A total of 4 special electrodes were attached and connected to the device. Electrodes were attached to the proximal side of the dorsal face of the hand and ankle, on the same side. The device makes measurements based on changing the conductivity and insulation property of the cell membrane by sending current in 50 different frequencies (between 5 and $1000 \mathrm{kHz}$ ). Measurements were completed for 1-2 minutes after entering age, weight, height data for each individual. The data was transferred to the computer via patient cards and analyzed using the fluid management system. Measurements were made just before the first HD treatment and after the last HD treatment before the discharge.

\section{Echocardiography}

Echocardiographic evaluations of all patients were performed immediately before beginning the first HD treatment and 2 hours after the last HD treatment before discharge. For the echocardiographic evaluation, services were received from the Adnan Menderes University Medical Faculty Hospital. Echocardiographic examination was performed by a single investigator with Philips brand model no HD11XE ultrasound system SN 2010-10 USD 10778319 with probe S3-1. After a 10-minute rest, the patient was recorded in the device's memory at the lateral decubitus position, at the end of the expiration, when necessary at short-term apnea periods, at a rate of $100 \mathrm{~mm} / \mathrm{sec}$. Averages of 3 consecutive measurements were taken in the assessments and recorded on the patient registration forms. Left atrial dimension was measured in the parasternal long axis plane. The left atrial dimension was measured at the end of the ventricular diastole and where the left atrium was largest. Atrial diameters were measured by 2D echocardiography in apical 4 space, 2 space and long axis planes and atrium volume was calculated according to the formulas specified (LA Volume $=0.85 \mathrm{XA} 1 \mathrm{XA} 2 / \mathrm{L}$, where A1 and A2 were areas measured in $2 \mathrm{ch}$ and $4 \mathrm{ch}$ views, respectively. $\mathrm{L}$ was the linear measurement acquired in two different ways, parallel to atrial septum or perpendicular to mitral annulus). ${ }^{7-9}$ To calculate the left atrium volume, measurements were made at the end of the left ventricular diastole at the time of the greatest left atrium just before opening the mitral valve.

\section{Statistical Methods}

Statistical Package for Social Sciences for Windows version 17 (SPSS Inc; Chicago, IL, USA) was used in statistical evaluations. Descriptive statistics were expressed as number $(\mathrm{n}, \%)$ and mean \pm standard deviation. The normal distribution suitability of the variables was examined by the Kolmogorov-Smirnov Test. T-test was used for independent groups and ANOVA for repeated measures was used to compare normal distribution variables. The Friedman ANOVA test was used to compare the variables without normal distribution. Multiple regression analysis was used to determine the factors affecting the AIx and PWV variables. The relationship of variables to each other was examined by Pearson Correlation Coefficient. $p<0.05$ was considered significant.

\section{Ethics Committee Approval}

Our study was presented to Adnan Menderes University Faculty of Medicine Clinical Investigation Ethics Committee and it was approved by 7 th decision of B.30.2.ADÜ.0.20.05.00 / 050.04-149 dated 14.06.2012.

TABLE 1: DEMOGRAPHIC DATA

\begin{tabular}{l|c|c|c}
\hline \multirow{2}{*}{} & \multicolumn{2}{|c|}{ Gender } & \multirow{2}{*}{ Total } \\
\cline { 2 - 4 } & Male & Female & $52(100 \%)$ \\
\hline Number of patients $(\mathrm{n}, \%)$ & $37(71,2 \%)$ & $15(28,8 \%)$ & $58,19 \pm 12,73$ \\
\hline Age $($ years $)$ & $56,54 \pm 12,81$ & $62,27 \pm 11,96$ & $163 \pm 10,44$ \\
\hline Height $(\mathrm{cm})$ & $167,56 \pm 7,60$ & $151,73 \pm 7,55$ & $71,71 \pm 15,35$ \\
\hline Weight $(\mathrm{kg})$ & $73,43 \pm 13,96$ & $67,46 \pm 18,13$ & $27,07 \pm 5,62$ \\
\hline Body Mass Index $\left(\mathrm{kg} / \mathrm{m}^{2}\right)$ & $26,17 \pm 4,36$ & $29,27 \pm 7,67$ & \\
\hline
\end{tabular}




\section{RESULTS}

Newly diagnosed patients with end-stage renal insufficiency and who planned to undergo renal replacement therapy were included in the study. Among the 52 patients diagnosed with end-stage renal failure, $71.2 \%(\mathrm{n}=37)$ were male and $28.8 \%(\mathrm{n}=15)$ were female. The mean age of all patients, male and female patients was $58,19 \pm 12,73$ (years old), 56,54 \pm 12,81 (years old) and $62,27 \pm 11,96$ (years old), respectively. The distributions of age, height, weight and body mass index values according to sex are shown in Table 1. CKD etiologic cause was hypertension in $44 \%$ of our patients, diabetes in $29 \%$, glomerulonephritis in $7 \%$ and amyloidosis in $6 \%$ of our patients. Etiological cause could not be determined in $6 \%$ of patients. Volumetric status, vascular access, medical treatment, cigarette use, hepatitis and HIV serological status of the studied patients are given in patient characteristics section.

\section{PATIENT CHARACTERISTICS}

Vascular access route: Transient HD catheter, arteriovenous fistula (AVF) and permanent HD catheter ratios were $50 \%, 19.2 \%$ and $30.8 \%$, respectively. Number of HD sessions reached dry weight (\%); specified below: Dry weight was reached in 4 sessions (13.5\%), 5 sessions (46.2\%), 6 sessions (19.2\%), 7 sessions (13\%) and $\geq 8$ sessions (7.6\%). Pretibial edema status (\%), specified below: $36.5 \%$ of the patients had no edema, $15.4 \%$ of the patients had edema in the

TABLE 2. BIOCHEMICAL AND BODY COMPOSITION PARAMETERS AFFECTED BY BODY FLUID STATUS

\begin{tabular}{l|l|l|l}
\hline & $\begin{array}{l}\text { Before } \\
\text { the HD }\end{array}$ & $\begin{array}{l}\text { After } \\
\text { treatment }\end{array}$ & p Value \\
\hline Hemoglobin (g/dL) & $9,21 \pm 1,52$ & $9,87 \pm 1,68$ & 0,008 \\
\hline Hematocrit $(\%)$ & $28,47 \pm 4,76$ & $30,44 \pm 5,35$ & 0,009 \\
\hline Sodium (mEq/L) & $136,15 \pm 5,83$ & $134,15 \pm 3,20$ & 0,012 \\
\hline Albumin (g/dL) & $3,08 \pm 0,61$ & $3,17 \pm 0,65$ & 0,164 \\
\hline BNP & $443,10 \pm 584,06$ & $560,64 \pm 2316,70$ & 0,705 \\
\hline Weight & $71,82 \pm 15,20$ & $67,44 \pm 14,96$ & $<0,001$ \\
\hline Overhydration & $2,52 \pm 3,28$ & $0,39 \pm 1,62$ & $<0,001$ \\
\hline LTI & $11,98 \pm 3,13$ & $11,07 \pm 2,74$ & $<0,001$ \\
\hline FTI & $13,98 \pm 7,06$ & $14,12 \pm 6,65$ & 0,556 \\
\hline BCM & $17,14 \pm 6,81$ & $15,37 \pm 6,02$ & $<0,001$ \\
\hline TBW & $33,38 \pm 6,44$ & $29,64 \pm 5,71$ & $<0,001$ \\
\hline ECW & $16,82 \pm 3,45$ & $14,10 \pm 2,64$ & $<0,001$ \\
\hline ICW & $16,65 \pm 3,85$ & $15,54 \pm 3,50$ & $<0,001$ \\
\hline
\end{tabular}

LTI: Lean Tissue Index, FTI: Fatty Tissue Index, ECW: Extra Cellular Water, ICW: Intra Cellular Water. amount of trace, $1+$ edema, 2+ edema, 3+ edema and $4+$ edema status were, $15,4 \%, 21,2 \%, 9,6 \%$ and 1,9 $\%$, respectively. Diuretic treatment status (\%), specified below: $46.2 \%$ of the patients were using diuretics and $53.8 \%$ were not using diuretics. Oral sodium bicarbonate intake status, (\%); specified below: 90.4\% of the patients were using oral sodium bicarbonate while $9.6 \%$ were not using oral sodium bicarbonate. Smoking status (\%); While $19.2 \%$ of the patients were already smoker, $28.8 \%$ quit smoking, $52 \%$ were never smoker. HBsAg / Anti-HCV / Anti-HIV status (\%); The rates of HBsAg positive, anti-HCV positive and anti-HIV positive patients were $7,7 \%, 0 \%$ and $0 \%$, respectively. The laboratory data of the patients were given below: The mean urea, creatinine, uric acid, total protein, albumin and bicarbonate (HCO3) values of the patients were $184,54 \pm 62,48 \mathrm{mg} / \mathrm{dl}, 6,41 \pm 2,70 \mathrm{mg} /$ $\mathrm{dl}, 8,18 \pm 2,52 \mathrm{mg} / \mathrm{dl}, 6,19 \pm 0,86 \mathrm{~g} / \mathrm{dL}, 3,08 \pm 0,61 \mathrm{~g} / \mathrm{dL}$ and $20,23 \pm 7,11 \mathrm{mEq} / \mathrm{L}$, respectively. The mean sodium, potassium, calcium, phosphorus, ALP and PTH values were $136,15 \pm 5,83 \mathrm{mEq} / \mathrm{L}, 4,45 \pm 0,69 \mathrm{mEq} / \mathrm{L}$, $7,97 \pm 1,16 \mathrm{mg} / \mathrm{dL}, 5,51 \pm 1,86 \mathrm{mg} / \mathrm{dL}, 110,73 \pm 67,46 \mathrm{U} / \mathrm{L}$ and $443,53 \pm 454,66$, respectively. The mean hemoglobin, hematocrit, ferritin and CRP values were $9,21 \pm 1,52 \mathrm{~g} / \mathrm{dL}, 28,47 \pm 4,76 \%, 237,68 \pm 232,20 \mathrm{ng} / \mathrm{mL}$ and $52,26 \pm 61,12 \mathrm{mg} / \mathrm{L}$, respectively. The mean total cholesterol, triglyceride, HDL and LDL cholesterol values were $174,67 \pm 45,05 \mathrm{mg} / \mathrm{dL}, 142,60 \pm 72 \mathrm{mg} / \mathrm{dL}$, $33,08 \pm 11,64 \mathrm{mg} / \mathrm{dL}$ and $112,57 \pm 33,53 \mathrm{mg} / \mathrm{dL}$.

Biochemical and body composition parameters that could be affected by body fluid status were compared before and after treatment (Table 2). Significant changes were detected in hemoglobin, hematocrit and sodium. In the body composition measurement to determine the body fluid state, all parameters except the fat tissue index decreased significantly after HD treatment (Table 2). PWV measurements made with mobilograph for arterial stiffness were found to be $8,84 \mathrm{~m} / \mathrm{s}$ before the first HD treatment and 8,38 $\mathrm{m} / \mathrm{s}$ after the last HD. It decreased significantly $(\mathrm{p}$ $=0.001$ ). Before the first HD and after the last HD treatment, arterial stiffness and echocardiographic parameters were compared. PWV, MAP, CO, pulse pressure, central systole, central diastole and central pulse pressures were also significantly correlated. There was a significant decrease in CTI, LA diameters and volumes after treatment (Table 3). Correlations between PWV and age and CTI were positive $(r=0.865 p<0.001$ and $r=0.301 p=0.030$, respectively) before HD treatment. Before HD treatment, 
negative correlations between PWV and LTM, ICW were detected $(r=-0,408, p=0,003$ and $r=-0,444, p$ $=0,001$, respectively). In the analysis of the measurements performed after the last HD, positive correlations were found between PWV and age, CTI, central pulse pressure $(r=0,884 p<0,001, r=0,348 p=$ $0,012, r=0,641 \mathrm{p}<0,000$, respectively) and negative correlation with LTI.

\section{DISCUSSION}

CV complications are the most important cause of death in ESRD. In the emergence of this complication, classical atherosclerosis risk factors as well as factors of chronic renal failure (CRF) play an important role. In the course of $\mathrm{CRF}$, vascular calcification, arterial stiffness, and accelerated atherosclerosis often develop prior to the stage of dialysis and transplantation. Vascular calcification and arterial stiffness are independent determinants of CVD risk in CRF. AIx, pulse pressure and PWV are the most important parameters showing arterial stiffness. It has been shown that central AIx and aortic PWV may be a more sensitive marker of arterial aging in younger individuals, and in those over 50 years of age, respectively. ${ }^{10}$ Patients on dialysis had better arterial stiffness parameters than predialysis stage 5 CKD patients, indicating that dialysis can improve arterial stiffness in patients with uremia. ${ }^{11}$ Progression of renal failure decreases the renal sodium excretion capacity and increases the incidence of hypertension due to extracellular volume increase. ${ }^{12}$ Volume expansion is one of the most important factors that results in higher levels of blood pressure in patients with CKD. ${ }^{13}$ Beyond causing hypertension, chronic fluid overload leads to an increase in PWV, an indicator of arterial stiffness, and left ventricular hypertrophy, which is closely related to mortality. ${ }^{14}$ It has been shown that excess fluid plays an important role in the development of arterial stiffness in dialysis patients by increasing arterial distension and systolic blood pressure. ${ }^{15}$ Both volume overload and angiotensin II may contribute to the decreased arterial compliance and increased AIx in HD patients. ${ }^{16}$ Aortic stiffness in HD patients is thought to be due, in part, to a reduction in aortic compliance associated with excess volume (which can be reversible). Öğünç et al. ${ }^{17}$ evaluated the changes occurring in PWV and AIx during a single HD ses- sion. The measurements obtained at 15-minute intervals showed a significant decrease in PWV that started at 135 minutes during HD and continued until 30 minutes after the end of the dialysis. Di Iorio et al. ${ }^{18}$ reported that PWV in HD patients underwent cyclic changes in a period of 1 week; PWV, hydration status, and blood pressure decreased during dialysis and increased in the interdialytic period. In our study, we aimed to investigate the effect of reducing the fluid excess and correcting the uremic state on the CV system in patients who reach dry weight after dialysis is started. The correlation of PWV with age and CTI before the first and after the last HD was determined. This is consistent with the fact that age is an independent variable in arterial stiffness. There was a decrease in all volumetric indicators with HD and a positive correlation between PWV and CTI was detected. HD treatment significantly improves PWV, which is indicative of arterial stiffness, in patients reaching dry weight. Decreased volume with ultrafiltration is associated with a decrease in all echocardiographic parameters. Benetos showed that elderly men with high lean mass and low-fat mass exhibit the best arterial profile with the lowest arterial stiffness in general population. ${ }^{19}$ In our study, there was a negative relationship between PWV and LTM (before HD) and PWV and LTI (after

TABLE 3. ARTERIAL STIFFNESS AND ECHOCARDIOGRAPHIC PARAMETERS BEFORE AND AFTER TREATMENT.

\begin{tabular}{l|l|l|l}
\hline & $\begin{array}{l}\text { Before } \\
\text { treatment }\end{array}$ & $\begin{array}{l}\text { After } \\
\text { treatment }\end{array}$ & P Value \\
\hline Heart rate & $83,58 \pm 14,52$ & $88,60 \pm 16,16$ & 0,054 \\
\hline Pulse wave velocity & $8,84 \pm 1,82$ & $8,38 \pm 2,07$ & 0,001 \\
\hline Augmentation Index & $26,5 \pm 12,61$ & $30,31 \pm 12,52$ & 0,078 \\
\hline Augmentation Pressure & $9,48 \pm 7,63$ & $7,50 \pm 5,65$ & 0,18 \\
\hline MAP & $107,15 \pm 17,37$ & $97,35 \pm 21,71$ & 0,007 \\
\hline CO & $4,91 \pm 2,39$ & $4,20 \pm 0,83$ & 0,040 \\
\hline Peripheral Resistance & $1,35 \pm 0,33$ & $1,29 \pm 0,19$ & 0,289 \\
\hline Cardiac Index & $2,56 \pm 0,53$ & $2,45 \pm 0,60$ & 0,184 \\
\hline Pulse Pressure & $54,67 \pm 17,25$ & $45,61 \pm 18 a, 27$ & 0,004 \\
\hline Central Systolic Pessure & $122,35 \pm 22,42$ & $109,02 \pm 26,12$ & 0,002 \\
\hline Central Diastolic Pressure & $85,27 \pm 15,12$ & $78 \pm 17,75$ & 0,019 \\
\hline Central Pulse Pressure & $38,75 \pm 13,43$ & $31,02 \pm 13,25$ & $<0,001$ \\
\hline CTI & $55,2 \pm 7,82$ & $48,31 \pm 5,48$ & $<0,001$ \\
\hline LA diameter & $3,70 \pm 0,51$ & $3,46 \pm 0,46$ & $<0,001$ \\
\hline LA volume - Elliptic & $46,12 \pm 17,90$ & $34,39 \pm 12,64$ & $<0,001$ \\
\hline LA volume - Biplane & $60,78 \pm 31,93$ & $44,88 \pm 22,54$ & $<0,001$ \\
\hline
\end{tabular}

MAP: Mean arteriel pressure, CTI: Cardiothoracic index 
HD); Indirectly, reduction in muscle mass may be important in increasing PWV and affecting arterial stiffness. This data supports the argument that better uremic clearance and better volume control can have positive results in arterial stiffness. ${ }^{17} \mathrm{In}$ our study, removal of excess fluid by ultrafiltration also led to an increase in hematocrit levels. Anemia usually develops during the course of CKD and may be associated with adverse outcomes. Anemia can lead to negative cardiac outcomes by inducing hypoxia and establishing the basis for $\mathrm{LVH}$, ischemic heart disease, congestive heart failure. Early detection and effective treatment of anemia due to the development of CVD and adverse effects on mortality is important in preventing these adverse events. In patients with ESRD, known classical CV risk factors are insufficient to explain the development of early atherosclerosis. Effective treatment of modifiable risk factors in patients with CRF may reduce morbidity and mortality due to CVD. Therefore, recognition of the factors affecting the development of early LVH are more common in patients with CKD due to the presence of excess fluid and anemia. Correct determination of dry weight of patients is an important parameter in preventing heart failure development. In addition, BNP levels increase as the progression of heart failure progresses. It is known that BNP levels begin to increase before an apparent volume expansion occurs. Volume expansion is an important problem in patients with initial HD treatment. Interdialytic fluid intake has been shown to be associated with mortality. Long-term dialysis treatments are thought to reduce mortality by eliminating uremic toxins as well as providing volume balance. In patients with CKD, the risk of CVD can be reduced by preserving residual renal functions by salt and fluid restriction. In HD patients without residual renal function, the contribution of volume load to arterial stiffness can be prevented by correctly determining the volume status of the patient. By means of routine use of arterial stiffness measurement and bioimpedance devices, the volume status of patients can be controlled. Thus, CVD in patients with CKD can be detected and treated in advance and their development slowed down. Reduction of fluid excess by ultrafiltration in HD patients may reduce $\mathrm{CV}$ mortality by reducing arterial stiffness. Routine follow-up of arterial stiffness and bioimpedance parameters besides echocardiography may be helpful in determining cardiovascular risk in patients undergoing HD.

\section{CONCLUSION}

Routine measurement of arterial stiffness and bioimpedance parameters may play an important role in monitoring the cardiovascular risks of hemodialysis patients.

\section{Acknowledgement}

This research was supported by Adnan Menderes University Scientific Research Projects Unit as TPF-12008 project. All authors declare there is no conflict of interest regarding the publication of this manuscript.

\section{RESUMO}

INTRODUÇÃO: Em pacientes com doença renal crônica (DRC), toxinas urêmicas e hipervolemia contribuem para aumentar o risco cardiovascular. Nosso objetivo foi determinar o estado de hidratação em pacientes com DRC iniciando hemodiálise (HD) e avaliar os efeitos da correção da hipervolemia sobre o sistema cardiovascular.

MÉTODOS: Foram incluídos 52 pacientes que haviam acabado de iniciar HD. Antes do início da sessão, foram determinados o diâmetro e o volume atrial esquerdo, a velocidade de onda de pulso (VOP) e o índice de amplificação sistólica ("augmentation index", Al). Além disso, realizamos análise da composição corporal por bioimpedância elétrica (BIA) e mensuramos os níveis plasmáticos de peptídeo natriurético tipo B. Os mesmos procedimentos foram repetidos após os pacientes alcançarem o "peso seco".

RESULTADOS: O peso corporal dos pacientes foi reduzido, em média, em 4,38 kg. Na BIA, todos os parâmetros, exceto o índice de gordura corporal, foram significativamente reduzidos após a hemodiálise. Antes da HD, a VOP se correlacionou positivamente com idade e razão cardiotorácica (RCT), e negativamente com a massa magra e a água intracelular. Ao final da hemodiálise, a VOP se correlacionou positivamente com idade, RCT e pressão de pulso central, correlacionando-se negativamente com a Lean Tissue Index (LTI).

CONCLUSÃO: A hemodiálise melhora a VOP por meio da redução da volemia. O controle da hipervolemia via ultrafiltração pode reduzir a mortalidade cardiovascular por meio da redução da rigidez arterial.

PALAVRAS-ChAVE: Análise de onda de pulso. Peptídeo natriurético encefálico. Nefropatias. Falência renal crônica. Impedância elétrica. Diálise renal. Composição corporal. 


\section{REFERENCES}

1. Süleymanlar G, Utas C, Arinsoy T, Ates $K$, Altun B, Altiparmak MR, et al. A population-based survey of Chronic REnal Disease In Turkey: the CREDIT study. Nephrol Dial Transplant. 2011;26(6):1862-71.

2. Tsai YC, Chiu YW, Tsai JC, Kuo HT, Hung CC, Hwang SJ, et al. Association of fluid overload with cardiovascular morbidity and all-cause mortality in stages 4 and 5 CKD. Clin J Am Soc Nephrol. 2015;10(1):39-46.

3. Jatoi NA, Mahmud A, Bennett K, Feely J. Assessment of arterial stiffness in hypertension: comparison of oscillometric (Arteriograph), piezoelectronic (Complior) and tonometric (SphygmoCor) techniques. J Hypertens. 2009;27(11):2186-91.

4. Horváth IG, Németh A, Lenkey Z, Alessandri N, Tufano F, Kis P, et al. Invasive validation of a new oscillometric device (Arteriograph) for measuring augmentation index, central blood pressure and aortic pulse wave velocity. | Hypertens. 2010;28(10):2068-75.

5. Baulmann |, Schillings U, Rickert S, Uen S, Düsing R, Illyes M, et al. A new oscillometric method for assessment of arterial stiffness: comparison with tonometric and piezo-electronic methods. J Hypertens. 2008;26(3):523-8.

6. MoissI UM, Wabel P, Chamney PW, Bosaeus I, Levin NW, Bosy-Westphal $A$, et al. Body fluid volume determination via body composition spectroscopy in health and disease. Physiol Meas. 2006;27(9):921-33.

7. Posina K, Passick M, Reichek N, Cao II. Left atrial volume measurement with magnetic resonance imaging: a comparison of biplane, short axis and long axis methods. J Cardiovasc Magn Reson. 2011;13(Suppl 1):P5.

8. Lester SJ, Ryan EW, Schiller NB, Foster E. Best method in clinical practice and in research studies to determine left atrial size. Am | Cardiol. 1999;84(7):829-32.

9. Madueme PC, Mazur W, Hor KN, Germann IT, lefferies IL, Taylor MD. Comparison of area-length method by echocardiography versus full-volume quantification by cardiac magnetic resonance imaging for the assessment of left atrial volumes in children, adolescents, and young adults. Pediatr Cardiol. 2014;35(4):645-51.

10. McEniery CM, Yasmin, Hall IR, Qasem A, Wilkinson IB, Cockcroft JR;
ACCT Investigators. Normal vascular aging: differential effects on wave reflection and aortic pulse wave velocity: the Anglo-Cardiff Collaborative Trial (ACCT). J Am Coll Cardiol. 2005;46(9):1753-60.

11. Yang $L$, Lin $Y$, Ye C, Mao Z, Rong S, Zhao X, et al. Effects of peritoneal dialysis and hemodialysis on arterial stiffness compared with predialysis patients. Clin Nephrol. 2011;75(3):188-94.

12. Charra B, Chazot C. Volume control, blood pressure and cardiovascular function. Lessons from hemodialysis treatment. Nephron Physiol. 2003;93(4):p94-101.

13. Weir MR. Hypervolemia and blood pressure: powerful indicators of increased mortality among hemodialysis patients. Hypertension. 2010;56(3):341-3

14. Akdam H, Öğünç H, Alp A, Özbek Ö, Ömürlü IK, Yeniçerioğlu Y, et al. Assessment of volume status and arterial stiffness in chronic kidney disease. Ren Fail. 2014;36(1):28-34

15. Zheng D, Cheng LT, Zhuang Z, GuY, Tang LJ, Wang T. Correlation between pulse wave velocity and fluid distribution in hemodialysis patients. Blood Purif. 2009;27(3):248-52.

16. Tycho Vuurmans |L, Boer WH, Bos WJ, Blankestijn PJ, Koomans HA. Contribution of volume overload and angiotensin II to the increased pulse wave velocity of hemodialysis patients. | Am Soc Nephrol. 2002;13(1):17783.

17. Öğünç $H, A k d a m H, A l p A$, Gencer $F, A k a r H$, Yeniçerioğlu Y. The effects of single hemodialysis session on arterial stiffness in hemodialysis patients. Hemodial Int. 2015;19(3):463-71.

18. Di lorio B, Nazzaro P, Cucciniello E, Bellizzi V. Influence of haemodialysis on variability of pulse wave velocity in chronic haemodialysis patients. Nephrol Dial Transplant. 2010;25(5):1579-83.

19. Benetos A, Zervoudaki A, Kearney-Schwartz A, Perret-Guillaume C, Pascal-Vigneron V, Lacolley P, et al. Effects of lean and fat mass on bone mineral density and arterial stiffness in elderly men. Osteoporos Int. 2009;20(8):1385-91. 